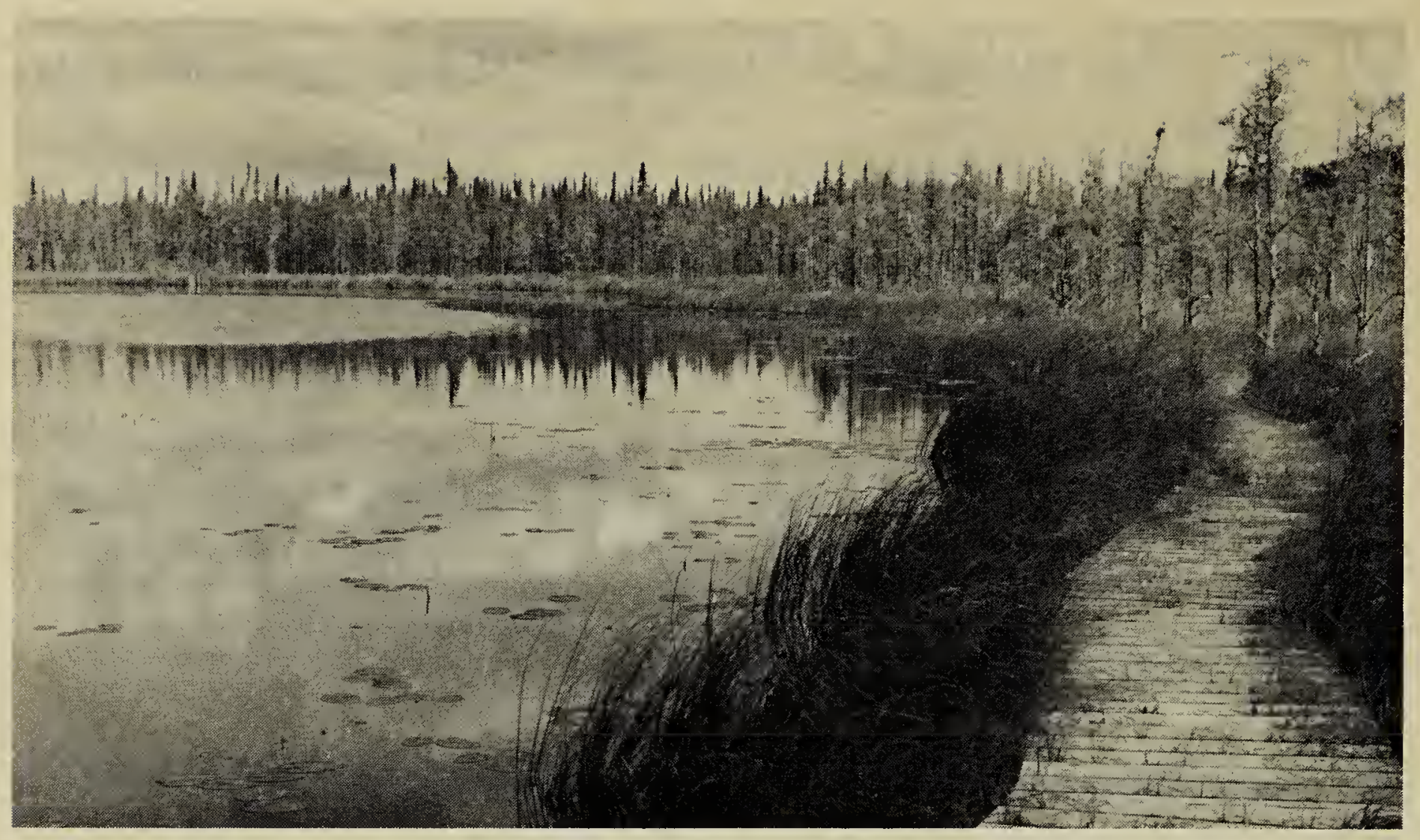

Boundary Bog Nature Trail, Prince Albert National Park

Parks Canada

Through the combined efforts of the provinces, and hundreds of groups and individuals 1985 will be a year of increased awareness of the need for protection of our natural and cultural heritage. We must also look to the future to the second century of parks and beyond. What will be the pressures of society and technology upon our national parks? How will we meet the challenges of completing the national parks system?

National parks give us a chance to glimpse the fascination of the real world, to observe life free of the dominating hand of man. They are places where we still have a hope of enjoying the sights and sounds and spirit of the untamed, unspoiled wilderness.

The Centennial of the national parks system is an occasion to reflect upon and celebrate past achievements and to step ahead towards further protection of the first Canada, wild Canada.

\section{CENTENNIAL ACTIVITIES IN SASKATCHEWAN}

Across the country this year, Canadians have been invited to join in the celebration of "100 Years of Heritage Conservation."

Interpretive activities in parks and historic sites will have a special emphasis during the Centennial. Come out and experience new excitement in your favorite programs. Spirits from the past and Boomer the Beaver, the National Parks' mascot, may be among the surprises that will liven up the show. Take part in Centennial events outside of parksexhibits in malls, special film presentations, and displays at fairs are some of the things that have been planned.

For specific details regarding projects and activities within Saskatchewan write to Brad Muir, Centennial Coordinator, Parks Canada, Prince Albert National Park, Box 100, Waskesiu Lake, Saskatchewan SOJ 2 YO or telephone 306-663-5322. 